\title{
Mixed Adenoneuroendocrine Carcinoma (MANEC) of the Gallbladder: A Systematic Review of Outcomes Following Surgical Management
}

\author{
NIKOLAOS MACHAIRAS ${ }^{1 *}$, ANNA PASPALA $^{1 *}$, MAXIMOS FROUNTZAS $^{2}$, DIAMANTIS I. TSILIMIGRAS $^{3}$, \\ DIMITRIOS MORIS ${ }^{4}$, VASILEIA NTOMI ${ }^{1}$, DIMITRIOS TSAPRALIS ${ }^{5}$ and DIMITRIOS SCHIZAS $^{6}$ \\ ${ }^{1} 3$ rd Department of Surgery, National and Kapodistrian University of Athens, \\ Attikon University Hospital, Athens, Greece; \\ ${ }^{2}$ Laboratory of Experimental Surgery and Surgical Research "N. S. Christeas", \\ National and Kapodistrian University of Athens, Athens, Greece; \\ ${ }^{3}$ Department of Surgery, Division of Surgical Oncology, \\ The Ohio State University Wexner Medical Center, Columbus, OH, U.S.A.; \\ ${ }^{4}$ Department of Surgery, Duke University Medical Center, Durham, NC, U.S.A.; \\ ${ }^{5}$ Department of Surgery, General Hospital of Ierapetra, Ierapetra, Greece; \\ ${ }^{6} 1$ st Department of Surgery, National and Kapodistrian University of Athens, Laikon Hospital, Athens, Greece
}

\begin{abstract}
Background/Aim: Mixed adenoneuroendocrine carcinomas (MANEC) are uncommon tumors exhibiting both adenocarcinomatous and neuroendocrine differentiation. They most commonly arise in the colon, appendix, rectum or stomach, however, a limited number of MANECs have been reported to originate in the gallbladder (gMANEC). The aim of our systematic review was to accumulate the existing data on gMANEC with special attention to the clinicopathological characteristics, surgical approach, recurrence and survival rates of patients diagnosed with this rare malignancy. Materials and Methods: A comprehensive search of the literature was undertaken. Results: A total of 15 studies (14 case reports and 1 case series), which comprised 19 patients who successfully underwent surgical treatment for gMANEC were included in our systematic review. During a median follow-up of 8 months (range=2-48 months) the overall
\end{abstract}

This article is freely accessible online.

*These Authors contributed equally and should both be considered first Authors.

Correspondence to: Nikolaos Machairas, 3nd Department of Surgery, University Hospital Attikon, Rimini Str. 1, 12462 Athens, Greece. Tel: +30 2105831000, e-mail: nmachair@gmail.com

Key Words: Gallbladder, MANEC, mixed, adenoneuroendocrine, carcinoma, review. survival was $87 \%$ and the recurrence rate was $21 \%$. Conclusion: Achievement of complete surgical resection is the mainstay of the therapeutic management. Additionally, the stage of the disease and the histopathological mapping of these tumors affect decision-making for adjuvant chemotherapy and seem to define the prognostic course of each patient.

Malignant tumors of the gallbladder are rarely encountered (1). Notwithstanding the fact that the gallbladder has a somewhat uncomplicated histological structure, a plethora of malignant lesions have been reported to arise from the gallbladder such as papillary and mucinous adenocarcinomas, squamous cell cancers, sarcomas and neuroendocrine tumors (1-4). Papillary adenocarcinoma is the most dominant histologic subtype accounting for approximately $98 \%$ of all gallbladder malignant tumors, while neuroendocrine tumors on the other hand are substantially uncommon accounting for a mere $0.5 \%(1,5)$. Mixed adenoneuroendocrine carcinomas (MANEC) are even more rarely diagnosed tumors, which combine both adenocarcinomatous and neuroendocrine differentiation (6). The concept of MANEC was first officially introduced by the World Health Organization classification of tumors of the digestive system in 2010 (7). MANECs constitute a rather particular group of tumors characterized by great heterogeneity as the percentages of adenocarcinomatous and neuroendocrine differentiation may vary greatly yet according to their definition; presence of each component in at least $30 \%$ of the tumor is mandatory (Figure 1) (6). 


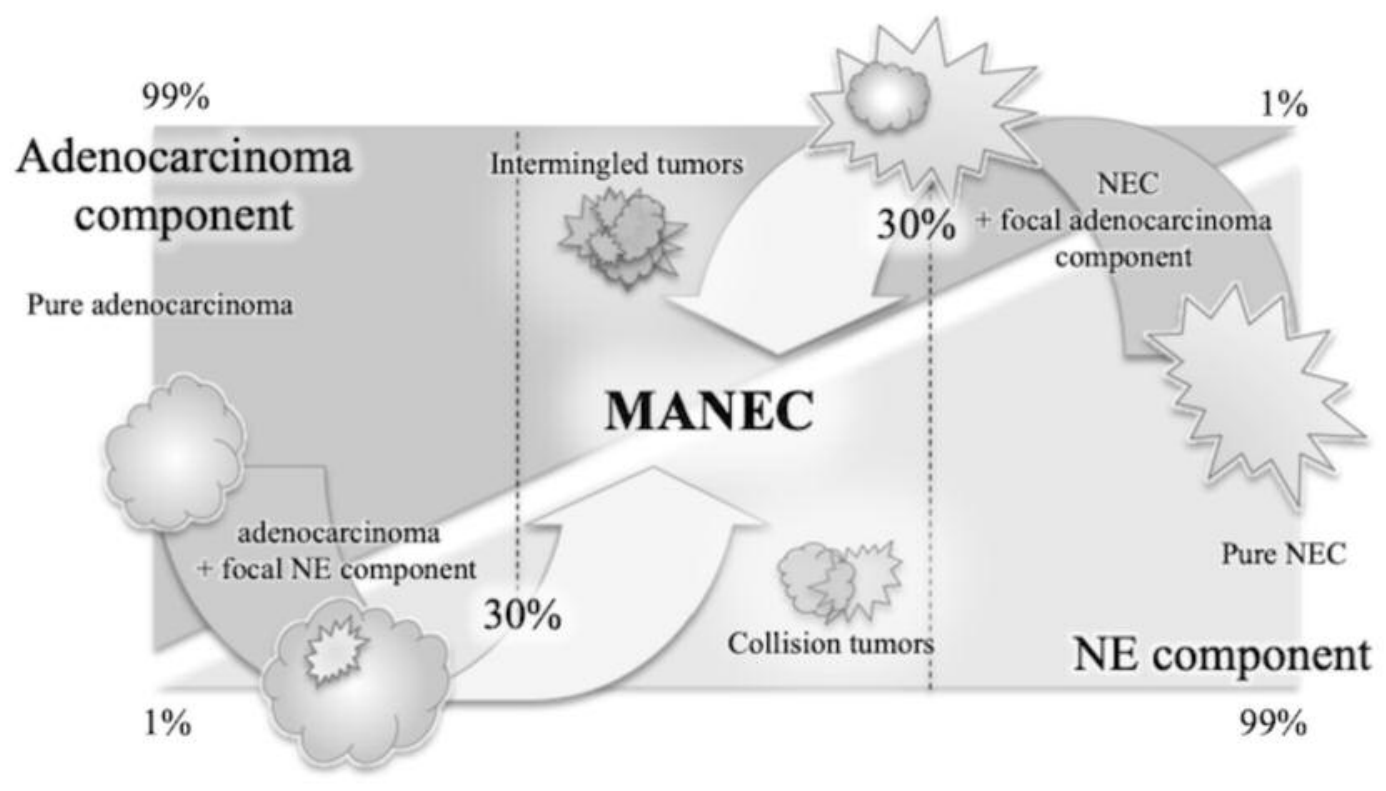

Figure 1. Place of MANEC within the spectrum of adenocarcinomatous and neuroendocrine components.

MANECs most commonly arise in the colon, appendix, rectum or stomach (8-11), however a limited number of MANECs have been reported to originate from the bile duct, the pancreas and the gallbladder (12-14).

Due to their rarity, outcomes of patients undergoing surgical management for gallbladder MANEC (gMANEC) remain ill determined. To that end the objective of our systematic review was to accumulate the existing evidence on gMANEC with special attention to the clinicopathological characteristics, surgical approach, recurrence and survival rates of patients diagnosed with this rare malignancy.

\section{Materials and Methods}

Study design. All appropriate observational studies and case reports, which addressed patients who were diagnosed with gMANEC and underwent surgical resection, were considered eligible for inclusion in our systematic review. Reviews and animal studies were excluded from analysis and tabulation. No language restrictions were applied.

Search strategy and data collection. A systematic search was performed for articles published up to June 2019 using the Medline, Scopus, and Google Scholar databases. The references within the retrieved articles were also retrieved in full text. The key words used for the search were the following: "gallbladder", "biliary tract", "MANEC", "mixed adenoneuroendocrine carcinoma", "composite adenoneuroendocrine carcinoma" and "combined adenoneuroendocrine carcinoma". In our attempt to assess an eligible number of studies that could be easily searched while simultaneously minimizing the potential loss of articles, a minimum number of search keywords were used. Articles fulfilling or deemed to fulfill the inclusion criteria were retrieved. All articles published from January 2000, which described patients aged $>18$ years who underwent surgical treatment for gMANEC were included. Data on patient characteristics included age and sex, while disease characteristics included primary symptoms, imaging studies performed to diagnose the lesions, administration and type of neoadjuvant treatment, type of surgery along with histopathological and immunochemical findings of the tumor. With regards to the main outcomes of the study, the follow-up period, mortality, administration of adjuvant treatment, and recurrence as well as survival rates were assessed.

\section{Results}

Included studies. A total of 15 studies (14 case reports and 1 case series), which comprised 19 patients who successfully underwent surgical treatment for gMANEC were considered eligible for inclusion and analysis in our systematic review as shown in Table I (14-28).

Main outcomes. The mean age of patients with gMANEC was $60 \pm 13$ years, whereas the male to female ratio was 0.36 (5 male and 14 female). As reported by 15 studies, the majority of patients presented with epigastric or right upper quadrant (RUQ) pain $(60 \%)$, while six $(40 \%)$ were asymptomatic at the timing of diagnosis. Preoperative liver function tests were abnormal in five cases $(15,17,20,26$, 28) while tumor markers were elevated in five patients (16, $17,20,26,28)$. Preoperative imaging studies were used in $68.4 \%(n=13$ out of 19$)$ of cases. Ten patients $(52.6 \%)$ had an abdominal computed tomography (CT), six (31.5\%) had 
Table I. Patients and tumor characteristics.

\begin{tabular}{|c|c|c|c|c|c|c|c|c|c|}
\hline $\begin{array}{l}\text { Author; } \\
\text { Year }\end{array}$ & $\mathrm{n}$ & $\begin{array}{l}\text { Age/ } \\
\text { Gender }\end{array}$ & $\begin{array}{l}\text { Primary } \\
\text { symptom }\end{array}$ & $\begin{array}{l}\text { Imaging } \\
\text { studies }\end{array}$ & $\begin{array}{l}\text { Neoadjuvant } \\
\text { chemo }\end{array}$ & Treatment & Stage & $\mathrm{CgA}$ & SynA \\
\hline Yannakou; 2001 & 1 & $72 / \mathrm{F}$ & $\begin{array}{l}\text { Epigastric pain, } \\
\text { nausea, weight loss }\end{array}$ & $\mathrm{CT}$ & No & $\mathrm{RC}$ & N/A & - & - \\
\hline Shimizu; 2006 & 1 & $58 / \mathrm{M}$ & Epigastralgia & $\mathrm{CT}$, angiography & No & Right hepatic trisegmentectomy & IVa & + & $\mathrm{N} / \mathrm{A}$ \\
\hline Oshiro; 2008 & 1 & $55 / \mathrm{F}$ & $\begin{array}{c}\text { Back pain, fever, } \\
\text { epigastralgia. }\end{array}$ & $\begin{array}{l}\text { CT, ERCP, PET, } \\
\text { MRI, MRCP, } \\
\text { EUS }\end{array}$ & No & $\begin{array}{l}\text { Pancreaticoduodenectomy, } \\
\text { gallbladder, bile duct, and liver } \\
\text { bed resection, LN dissection }\end{array}$ & IIIa & + & + \\
\hline Sato; 2010 & 1 & $68 / \mathrm{F}$ & No & $\mathrm{U} / \mathrm{S}, \mathrm{CT}$ & No & RC, 4 and 5 liver segmentectomy & N/A & + & + \\
\hline Chatterjee; 2014 & 1 & $73 / \mathrm{F}$ & No & $\mathrm{CT}$ & No & $\mathrm{RC}$ & I & + & + \\
\hline Mondolfi; 2011 & 1 & $48 / \mathrm{F}$ & $\begin{array}{l}\text { Epigastric RUQ } \\
\text { pain }\end{array}$ & US, PET & No & $\begin{array}{l}\text { Extended left lobectomy, } \\
\text { partial right hepatectomy }\end{array}$ & N/A & + & + \\
\hline Song; 2012 & 1 & $55 / \mathrm{F}$ & Epigastric pain & US, CT, PET & Yes & $\begin{array}{l}\mathrm{RC} \text { and } \mathrm{LN} \text { dissection in } \\
\text { hepatodudenal ligament and } \\
\text { common hepatic artery }\end{array}$ & IIIa & + & + \\
\hline Shintaku; 2013 & 1 & $80 / \mathrm{M}$ & No & N/A & No & $\mathrm{RC}$ & N/A & + & + \\
\hline Abe; 2013 & 1 & $81 / \mathrm{F}$ & No & US, CT, MRI & No & $\mathrm{RC}$ & N/A & + & + \\
\hline Meguro; 2014 & 1 & $54 / \mathrm{F}$ & Epigastric pain & $\begin{array}{l}\text { CT, ERCP, } \\
\text { MRCP }\end{array}$ & No & $\begin{array}{l}\mathrm{RC}, \text { Extrahepatic bile duct } \\
\text { resection, } \mathrm{LN} \text { dissection, and } \\
\text { hepaticojejunostomy }\end{array}$ & II & + & + \\
\hline Chen; 2014 & 1 & $34 / \mathrm{M}$ & RUQ pain & US, CT & No & $\mathrm{RC}$ and radical $\mathrm{LN}$ dissection & N/A & + & + \\
\hline Acosta; 2015 & 1 & $55 / \mathrm{F}$ & $\begin{array}{l}\text { Epigastric and } \\
\text { RUQ pain }\end{array}$ & US & No & $\begin{array}{l}\text { Robotic-assisted LC } \\
\text { \& Revision surgery }\end{array}$ & N/A & + & + \\
\hline Azad; 2015 & 1 & $62 / \mathrm{F}$ & No & $\mathrm{CT}$ & No & $\mathrm{RC}$ & N/A & N/A & + \\
\hline \multirow[t]{5}{*}{ Kanetkar; 2018} & 1 & $77 / \mathrm{F}$ & N/A & N/A & Yes & $\mathrm{RC}$ & IIIb & N/A & N/A \\
\hline & 1 & $63 / \mathrm{F}$ & No & N/A & No & Revision RC & II & N/A & N/A \\
\hline & 1 & $50 / \mathrm{M}$ & N/A & N/A & No & Revision RC & II & N/A & N/A \\
\hline & 1 & $47 / \mathrm{F}$ & N/A & N/A & No & $\mathrm{RC}$ & IIIa & N/A & $\mathrm{N} / \mathrm{A}$ \\
\hline & 1 & $64 / \mathrm{F}$ & N/A & N/A & No & $\mathrm{RC}$ & IIIb & N/A & N/A \\
\hline Lin; 2018 & 1 & $43 / \mathrm{F}$ & RUQ pain & MRI & No & $\begin{array}{l}\mathrm{RC} \text {, partial liver resection, } \\
\text { radical LN dissection }\end{array}$ & IIIa & + & + \\
\hline
\end{tabular}

n: Number of patients; CgA: chromogranin A; SynA: synaptophysin A; F: female; M: male; CT: computed tomography; ERCP: endoscopic retrograde choledochopancreatography, MRCP: magnetic resonance cholangiopancreatography; US: ultrasound; RC: radical cholecystectomy; LN: lymph node; RUQ: right upper quadrat; N/A: not available.

an abdominal ultrasound (US), three $(15.7 \%)$ a positron emission tomography (PET) and three $(15.7 \%)$ patients were diagnosed with magnetic resonance tomography (MRI), preoperatively.

Preoperative diagnosis of gallbladder carcinoma was established in six $(31.5 \%)$ cases; in four of them preoperative biopsy was utilized $(14,17)$, while in the other four PET and endoscopic ultrasound (EUS) were used $(26,28)$. Considering the locally advanced stage of disease at the time of diagnosis, two patients $(10.5 \%)$ received preoperative neoadjuvant chemotherapy with favorable response. One patient received carboplatin, paclitaxel, VP16 and octreotide for four cycles as a neoadjuvant chemotherapy and the other one received three cycles of carboplatin and etoposide $(14,17)$. All 19 patients underwent surgical resection; eight $(42.1 \%)$ underwent radical cholecystectomy (RC), three (15.7\%) patients had RC with lymph node dissection, two (10.5\%) cases underwent revision $\mathrm{RC}$, one had RC with extrahepatic bile duct resection and lymph node dissection, one (5.2\%) had revision RC after robotic-assisted laparoscopic cholecystectomy, one patient underwent right hepatic trisegmentectomy (5.2\%), one patient had pancreaticoduodenectomy, $\mathrm{RC}$, bile duct resection and lymph node dissection (5.2\%), one more had RC with segment $\mathrm{IV}$ and $\mathrm{V}$ liver resection $(5.2 \%)$ and one (5.2\%) patient underwent extended left hepatectomy. Immunohistochemistry staining analysis revealed positive expression of Chromogranin A (CgA) and Synaptophysin (SynA) in $92.3 \%$ of patients.

Long-term outcomes. Twelve studies reported long-term outcomes for 16 patients. Seven $(36.8 \%)$ patients received adjuvant chemotherapy postoperatively. Five (71.4\%) patients received carboplatin and etoposide for three cycles, one $(14.2 \%)$ patient received three cycles of carboplatin, paclitaxel, VP16 and octreotide and one (14.2\%) case received six cycles of cisplatin, etoposide and octreotide (14, $17,24)$. Two patients refused to continue their treatment with 
adjuvant chemotherapy postoperatively $(20,21)$. Two patients started intra-arterial chemotherapy and adjuvant chemotherapy after the presentation of recurrences $(21,28)$. During a median overall follow-up of eight months (range $=2-48$ months) the overall survival was $87 \%$, whereas four $(21 \%)$ patients reportedly presented with recurrence of disease within a median postoperative time of four months (range $=2-11$ months). Two patients died 2 and 3 months postoperatively due to disease progression.

\section{Discussion}

Mixed adenoneuroendocrine carcinomas of the gallbladder (gMANEC) are rather uncommon malignant tumors, whilst the vast majority of available data on these malignant lesions derive from case reports and small case series. Taking this limitation into account, our study group tried to collect all the available data in order to present the clinical features of the patients that suffer from gMANEC, the pre-operative imaging modalities used, as well as the possible diagnostic immunohistochemical markers, such as Synaptophysin (SynA) and Chromogranin A (CgA). In addition, we reported the therapeutic choices of gMANEC that have been recorded so far, including the pre-operative administration of neoadjuvant chemotherapy, the type of surgical excision and the additional administration of adjuvant chemotherapy after surgery. Finally, we listed all the available outcomes of the patients that had undergone a surgical procedure due to gMANEC, including the disease-free survival rates, the overall survival rates, the possibility of recurrences and the cancer-related deaths.

The histopathogenic pathways of the evolution of mixed component tumors of the gallbladder remain hard to determine. One theory supports that the two distinctly different components may evolve in an independent fashion synchronously or metachronously or one component may metachronously derive from the other (16). Meanwhile, others support the hypothesis of both morphologically distinctive carcinomas arising from a common, multipotent stem or progenitor cell (16). As far as the histology of these rare tumors is concerned, interesting findings have been observed $(8,29)$. Features of ordinary adenocarcinoma are usually recognized in the tumor surface, the neuroendocrine component has been recognized in areas of vascular and perineural infiltration, while neuroendocrine components were prominent in lymph node involvement cases (29). In that setting, outcomes of preoperative biopsies of these lesions may be misleading as the neuroendocrine component is not easily or adequately recognized. Notably, it has also been observed that the neuroendocrine cancer (NEC) component may display higher proliferative activity than the adenocarcinomatous component, possibly implying that the neuroendocrine part (NEC) in biliary MANEC could dictate long-term outcomes in these patients $(11,29)$. As far as the immunohistochemical profile of these tumors is concerned, a minimum of two out of three regularly used markers, namely SynA, CgA and Cluster of Differentiation 56 (CD56), ought to be diffusely expressed to confirm the diagnosis of high-grade MANEC (30). In our study, both the expression of CgA and SynA were positive in $92.3 \%$ of patients.

It is acknowledged that long-term outcomes in these patients are largely dependent on the most aggressive component (adenocarcinoma/NEC) of their tumor $(8,31,32)$. Long-term outcomes for patients with gallbladder neuroendocrine tumors have been shown to vary highly possibly due to their divergent disease stage and differentiation degree; 5-year survival rates range from approximately $37 \%$ to $60 \%(17,33)$ whereas the addition of the adenocarinomatous component is thought to dictate worse prognosis.

The optimal treatment strategy for these tumors remains largely undetermined $(6,32)$. Notably, two of the included studies reported administration of neoadjuvant treatment resulting in successful resection of gMANEC in two patients initially deemed unresectable; one patient received carboplatin, paclitaxel, VP16 and octreotide for four cycles and the other one received three cycles of carboplatin and etoposide $(14,17)$. Such cases indicate that there may potentially be room in the future for administration of neoadjuvant treatment in selected patients with consequent beneficial outcomes, however, the currently available data to support such practice remain limited. Complete surgical resection (R0) should be pursued whenever possible and has been associated with improved survival rates (32). Surgical treatment of these tumors may range widely, and may range from simple cholecystectomy to minor hepatectomy with concomitant lymph node dissection and eventually extrahepatic bile duct resection depending on the extent of tumor invasion as assessed perioperatively. As a result of their heterogeneity and rarity, which lead to a failure to standardize chemotherapeutic regimens of choice, the efficacy of adjuvant chemotherapy is ill determined, however there is increasing data suggesting its efficacy in selected patients $(34,35)$. The choice of chemotherapeutic regimens to be used lies on the degree of MANEC differentiation and accordingly may follow a "treat-like-neuroendocrine tumor" or a "treat-like-an adenocarcinoma" protocol as suggested by previous investigators (32).

To the best of our knowledge this is the first systematic review to assess outcomes in patients with gMANEC who have undergone curative-intent resection. On the other hand, a number of limitations inherent to our study need to be addressed prior to reaching conclusions. Initially, the majority of the included studies were vastly restricted to case reports and a small case series not allowing further analysis of outcomes. Moreover, the retrospective nature of the included studies constitutes another limitation. Finally, another limitation is the significant heterogeneity among the 
included studies, along with the fact that some critically important parameters, such as tumor differentiation, were not adequately presented.

\section{Conclusion}

The rarity of gMANEC remains the most significant obstacle in order to reach the most efficient standard practice. Nevertheless, the atypical clinical presentation of patients with symptoms or signs resembling cholecystitis should raise the suspicion of a malignant condition. Unfortunately, gMANEC is a histopathologic diagnosis, thus most of the times it is demonstrated post-operatively and confirmed by the expression of SynA and CgA. In cases where preoperative diagnosis is feasible, for example with the utilization of EUS, neo-adjuvant chemotherapy seems to be beneficial for some patients. Complete surgical resection is the mainstay of therapeutic management. Additionally, the stage of the disease and the histopathological mapping of the lesion could affect decision-making for adjuvant chemotherapy, but ultimately these two elements seem to define the prognostic course of each patient. Consequently, in order to evaluate the optimal diagnostic and therapeutic strategies for gMANEC, the enlargement of the available literature and the design of further trials are required.

\section{Conflicts of Interest}

The Authors declare no conflicts of interest regarding this study.

\section{Authors' Contributions}

Conceptualization: NM; Literature search and analysis: AP, MF; Data extraction: AP, MF, VD; Table drafting: AP, MF, VD; Manuscript editing: NM, DM, DIT, DT, DS Critical revision of the manuscript for important intellectual content: NM, DS; All Authors have read and approved the final version of this manuscript.

\section{References}

1 Kanthan R, Senger JL, Ahmed S and Kanthan SC: Gallbladder cancer in the 21st century. J Oncol 2015: 967472, 2015. PMID: 26421012. DOI: $10.1155 / 2015 / 967472$

2 Fujii Y, Tsuruga Y, Sakamoto S, Shomura H and Kazui K: Primary mixed neuroendocrine nonneuroendocrine neoplasm of the gallbladder associated with pancreaticobiliary maljunction without bile duct dilation. Am Surg 85: e74-e6, 2019. PMID: 30819309 .

3 da Costa AC, Santa-Cruz F, Sena BF, Lopes A, Leite N, da Paz AR, Ferraz AAB and Figueiredo JL: Dedifferentiated liposarcoma of the gallbladder: first reported case. World J Surg Oncol 16: 221, 2018. PMID: 30419915. DOI: 10.1186/s12957-018-1520-5

4 Rivero-Soto RJ, Hossein-Zadeh Z, Coleman J and Ahuja V: A mucinous cystic neoplasm originating from the gallbladder: a case report and literature review. Perm J 23, 2019. PMID: 30939279. DOI: 10.7812/TPP/18-077
5 Iype S, Mirza TA, Propper DJ, Bhattacharya S, Feakins RM and Kocher HM: Neuroendocrine tumours of the gallbladder: three cases and a review of the literature. Postgrad Med J 85: 213-218, 2009. PMID: 19417172. DOI: 10.1136/pgmj.2008.070649

6 La Rosa S, Marando A, Sessa F and Capella C: Mixed adenoneuroendocrine carcinomas (MANECs) of the gastrointestinal tract: An update. Cancers (Basel) 4: 11-30, 2012. PMID: 24213223. DOI: $10.3390 /$ cancers4010011

7 Bosman F, Carneiro F, Hruban R and Theise N: WHO Classification of Tumors of the Digestive Tract. 4th Edition. World Health Organization, Geneva. 2010.

8 Paspala A, Machairas N, Prodromidou A, Spartalis E, Ioannidis A, Kostakis ID, Papaconstantinou D and Nikiteas N: Management of MANEC of the colon and rectum: A comprehensive review of the literature. Mol Clin Oncol 9: 219-222, 2018. PMID: 30101026. DOI: $10.3892 / \mathrm{mco} .2018 .1649$

9 Brathwaite S, Yearsley MM, Bekaii-Saab T, Wei L, Schmidt CR, Dillhoff ME, Frankel WL, Hays JL, Wu C and Abdel-Misih S: Appendiceal mixed adeno-neuroendocrine carcinoma: A population-based study of the Surveillance, Epidemiology, and End Results Registry. Front Oncol 6: 148, 2016. PMID: 27379210. DOI: $10.3389 /$ fonc.2016.00148

10 Chen H, Shu M, Chen S, Xue L and Lin Y: Clinicopathological features and lymph node metastatic patterns of gastric mixed adenoneuroendocrine carcinoma. Histol Histopathol 34: 373-379, 2019. PMID: 30238962. DOI: $10.14670 / \mathrm{HH}-18-045$

11 Duzkoylu Y, Aras O, Bostanci EB, Keklik Temucin T and Ulas M: Mixed adeno-neuroendocrine carcinoma; case series of ten patients with review of the literature. Balkan Med J 35: 263267, 2018. PMID: 29551754. DOI: 10.4274/balkanmedj. 2017.1471

12 Acosta AM and Wiley EL: Primary biliary mixed adenoneuroendocrine carcinoma (MANEC): A Short Review. Arch Pathol Lab Med 140: 1157-1162, 2016. PMID: 27684986. DOI: 10.5858/arpa.2015-0102-RS

13 Mori H, Hanada K, Minami T, Yano S, Fukuhara M, Maruyama H, Shimizu A, Hirano N, Hino F, Amano H and Yonehara S: A case of mixed adenoneuroendocrine carcinoma of the pancreas mimicking intraductal papillary mucinous carcinoma. Clin J Gastroenterol 11: 320-326. 2018. PMID: 29442219. DOI: 10.1007/s12328-018-0833-9

14 Kanetkar AV, Patkar S, Khobragade KH, Ostwal V, Ramaswamy A and Goel M: Neuroendocrine carcinoma of gallbladder: a step beyond palliative therapy, experience of 25 cases. J Gastrointest Cancer 50: 298-303, 2019. PMID: 29435905. DOI: 10.1007/ s12029-018-0070-y

15 Yannakou N, Rizos S, Parissi-Mathiou P, Smailis D, Charanioti $\mathrm{S}$ and Dervenis C: Mixed (composite) glandular-endocrine cell carcinoma of the gallbladder. HPB (Oxford) 3: 7-9, 2001. PMID: 18333007. DOI: $10.1080 / 136518201753173782$

16 Paniz Mondolfi AE, Slova D, Fan W, Attiyeh FF, Afthinos J, Reidy J, Pang Y and Theise ND: Mixed adenoneuroendocrine carcinoma (MANEC) of the gallbladder: a possible stem cell tumor? Pathol Int 61: 608-614, 2011. PMID: 21951672. DOI: 10.1111/j.1440-1827.2011.02709.x

17 Song W, Chen W, Zhang S, Peng J and He Y: Successful treatment of gallbladder mixed adenoneuroendocrine carcinoma with neo-adjuvant chemotherapy. Diagn Pathol 7: 163, 2012. PMID: 23186166. DOI: 10.1186/1746-1596-7-163 
18 Shintaku M, Kataoka K and Kawabata K: Mixed adenoneuroendocrine carcinoma of the gallbladder with squamous cell carcinomatous and osteosarcomatous differentiation: report of a case. Pathol Int 63: 113-119, 2013. PMID: 23464969. DOI: 10.1111/pin.12029

19 Abe T, Kajiyama K, Harimoto N, Gion T, Shirabe K and Nagaie $\mathrm{T}$ : Composite adeno-endocrine carcinoma of the gallbladder with long-term survival. Int J Surg Case Rep 4: 504-507, 2013. PMID: 23562903. DOI: 10.1016/j.ijscr.2013.02.013

20 Meguro Y, Fukushima N, Koizumi M, Kasahara N, Hydo M, Morishima K, Sata N, Lefor AT and Yasuda Y: A case of mixed adenoneuroendocrine carcinoma of the gallbladder arising from an intracystic papillary neoplasm associated with pancreaticobiliary maljunction. Pathol Int 64: 465-471, 2014. PMID: 25146100. DOI: $10.1111 /$ pin.12188

21 Chen H, Shen YY and Ni XZ: Two cases of neuroendocrine carcinoma of the gallbladder. World J Gastroenterol 20: 1191611920, 2014. PMID: 25206300. DOI: 10.3748/wjg.v20.i33. 11916

22 Acosta AM, Hamedani FS, Kajdacsy-Balla A and Wiley EL: Primary mixed adenoneuroendocrine carcinoma of the gallbladder in a 55-year-old female patient: a case report and review of the literature. Int J Surg Pathol 23: 414-418, 2015. PMID: 25838330. DOI: 10.1177/1066896915580433

23 Azad S, Shukla D, Garg A, Negi SS and Malhotra V: Mixed adenoneuroendocrine carcinoma of the gallbladder, histopathological features. Indian J Pathol Microbiol 58: 543-545, 2015. PMID: 26549089. DOI: 10.4103/0377-4929.168879

24 Lin YX, Jia QB, Fu YY and Cheng NS: Mixed adenoneuroendocrine carcinoma of the gallbladder. J Gastrointest Surg 22: 1452-1454, 2018. PMID: 29313288. DOI: 10.1007/s11605-0173664-y

25 Chatterjee $\mathrm{D}$ and Wang $\mathrm{H}$ : Mixed adenoneuroendocrine carcinoma arising in a papillary adenoma of gallbladder. Am J Cancer Case Rep 2: 37-42, 2014.

26 Oshiro H, Matsuo K, Mawatari H, Inayama Y, Yamanaka S, Nagahama K, Endo I, Shimada H, Nakajima A and Kubota K: Mucin-producing gallbladder adenocarcinoma with focal small cell and large cell neuroendocrine differentiation associated with pancreaticobiliary maljunction. Pathol Int 58: 780-786, 2008. PMID: 19067853. DOI: 10.1111/j.1440-1827.2008.02311.x

27 Sato K, Imai T, Shirota Y, Ueda Y and Katsuda S: Combined large cell neuroendocrine carcinoma and adenocarcinoma of the gallbladder. Pathol Res Pract 206: 397-400, 2010. PMID: 19945229. DOI: 10.1016/j.prp.2009.10.008
28 Shimizu T, Tajiri T, Akimaru K, Arima Y, Yoshida H, Yokomuro S, Mamada Y, Taniai N, Mizuguchi Y and Kawahigashi Y: Combined neuroendocrine cell carcinoma and adenocarcinoma of the gallbladder: report of a case. J Nippon Med Sch 73: 101105, 2006. PMID: 16641536.

29 Harada K, Sato Y, Ikeda H, Maylee H, Igarashi S, Okamura A, Masuda S and Nakanuma Y: Clinicopathologic study of mixed adenoneuroendocrine carcinomas of hepatobiliary organs. Virchows Arch 460: 281-289, 2012. PMID: 22358181. DOI: 10.1007/s00428-012-1212-4

$30 \mathrm{Yu}$ J, Nikiforova MN, Hodak SP, Yim JH, Cai G, Walls A, Nikiforov YE and Seethala RR: Tumor-to-tumor metastases to follicular variant of papillary thyroid carcinoma: histologic, immunohistochemical, and molecular studies of two unusual cases. Endocr Pathol 20: 235-242, 2009. PMID: 19707890. DOI: 10.1007/s12022-009-9087-x

31 Hervieu V and Scoazec JY: Mixed endocrine tumors. Ann Pathol 25: 511-528, 2005. DOI: 10.1016/S0242-6498(05)86164-4

32 de Mestier L, Cros J, Neuzillet C, Hentic O, Egal A, Muller N, Bouche O, Cadiot G, Ruszniewski P, Couvelard A and Hammel $P$ : Digestive system mixed neuroendocrine-non-neuroendocrine neoplasms. Neuroendocrinology 105: 412-425, 2017. PMID: 28803232. DOI: $10.1159 / 000475527$

33 Eltawil KM, Gustafsson BI, Kidd $M$ and Modlin IM: Neuroendocrine tumors of the gallbladder: an evaluation and reassessment of management strategy. J Clin Gastroenterol 44: 687-695, 2010. PMID: 20375728. DOI: 10.1097/MCG.0b013 e3181d7a6d4

34 Watanabe J, Suwa Y, Ota M, Ishibe A, Masui H, Nagahori K, Tsuura $\mathrm{Y}$ and Endo I: Clinicopathological and prognostic evaluations of mixed adenoneuroendocrine carcinoma of the colon and rectum: A case-matched study. Dis Colon Rectum 59: 1160-1167, 2016. PMID: 27824701. DOI: 10.1097/DCR.00 00000000000702

35 Apostolidis L, Bergmann F, Jaeger D and Winkler EC: Treatment outcomes of patients with mixed adenoneuroendocrine carcinoma (MANEC). J Clin Oncol 33: e15187, 2015. DOI: $10.1200 /$ jco.2015.33.15_suppl.e15187

Received July 20, 2019

Revised August 4, 2019 Accepted August 5, 2019 